\title{
Does the global warming modify the local Rwandan climate?
}

\author{
Sascha M. Henninger
}

Department of Physical Geography, University of Kaiserslautern, Kaiserslautern, Germany; sascha.henninger@,ru.uni-k1.de

Received 2 November 2012; revised 8 December 2012; accepted 17 December 2012

\begin{abstract}
Analyses of climate measurement series from Rwandan weather stations revealed that the division into the four formerly described Rwandan climate zones is not correct any more. This could be shown in a more detailed analysis based on currently available data. In the course of discussions held with the Service Meteo Rwanda it emerged that the climate charts used in Rwandan atlases and school books are based on data covering the period from 1931 to 1960 . Fortunately, since then a mass of new data have been collected, which, however, until now have only been evaluated in isolated instances for a specific local as needed. This led to the initiation of the ReCCiR project. The project's aim was to conduct a regional climatic analysis covering all of Rwanda and visualizing it on new maps.
\end{abstract}

Keywords: Rwanda; Climate Change; Climate Zones; Central Africa

\section{INTRODUCTION}

Rwanda, located in central Africa, covers $26,338 \mathrm{~km}^{2}$, making it one of Africa's smallest states by area. Landlocked, it is surrounded by four neighboring countries: Uganda in the north, Tanzania in the east, Burundi, in the south and the Democratic Republic of Congo in the west. The Central African spurs of the East African Rift Valley, which separates the savannas of African highlands from the lowland forests of the Congo, shape Rwanda's morphology and landscape. Geologically recent uplifting of the East African Rift system gives Rwanda the high relief intensity that is characteristic for its geographical make up.

The East Rwandan high plains ("Plateau orientale") covers the area between the middle section of the Akagera River and the south to north flowing Akanyaru River's course. The Akagera system's drainage area shapes the morphology of this area. The Akagera in particular and its tributaries have cut deeply into the landscape. The valley bottoms for the most part are marshy (Figure 1). The Central Highlands ("Plateau central") are a crystalline mountainous area [1]. In the east, they abut the East Rwandan high plains. The "Plateau central" is marked by the east-facing rim of the Central African Rift Valley, which, starting from 1800 meters (at the border with Burundi) rises to almost 3000 m.a.s.l. Profoundly weathered gneisses and granites cover a large area. Aided by the steep gradient, smaller streams flowing out of the mountain ranges have left surface areas severely fragmented. The high relief intensity, especially marked here in the Central Highlands, has helped Rwanda earn the sobriquet "Land of a thousand hills" ("pays aux milles collines"). Eventually, the edge of the trench drops down about 1000 meters into the Central African Rift Valley where they join up in the west [1]. Lake Kivu had been dammed up by volcanic lava flows, later filling a large portion of the roughly $40 \mathrm{~km}$-wide Rift zone. The lake's surface lies at 1460 m.a.s.l. The Ruizi River forms the border with Democratic Republic of Congo. Since it burst through a volcanogenic blockage, it flows toward Lake Tanganyika, which sits at an elevation of only 773 meters. In the northwest, the Virunga volcanic chain runs along the border with Uganda and the Democratic Republic of Congo. The volcanoes sit on top of a system of fissures in an area alongside the Central African Rift [3] (Figure 1). This range of volcanoes with its several peaks rose up during the Tertiary and has remained active to the present day. All but one of the Virungas (Sabinyo) are cone-shaped volcanoes, characterized by eruptions of the Strombolian type. The massif's peaks range between 3500 and 4500 meters in elevation. In its middle sits Karisimbi, at 4507 meters Rwanda's highest mountain, also named "the white shell" for the snow that occasionally covers its peak. South of the Virungas, between 1400 and 2200 m.a.s.l., stretches a vast lava field.

Viewed in its totality, Rwanda's relief development is characterized by an intensive overlaying of (pre)tertiary erosion surfaces. Responsible in particular for these are uplifts and faulting since the Miocene. Exposed to epirogenetic processes since the Paleozoic, the Gondwana 


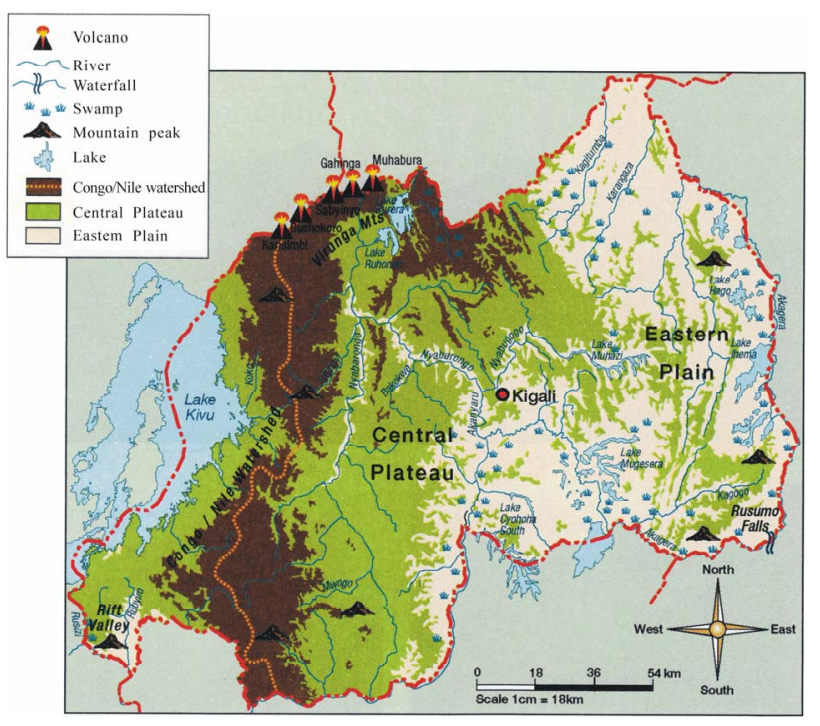

Figure 1. Rwanda: physical features [2].

block was subjected to repeated erosion episodes; however, because of its proximity to the East African Rift system, it underwent increasingly taphrogenic processes [3]. It was the change from denudation in times of tectonic peace to intensive faulting resulting from strong, young upliftings which finally imprinted Rwanda's surface as it appears today. Besides the endogenous processes, accelerated slope erosion is evidently intensifying almost everywhere in the country. However, it is also apparent, judging by massive valley and slope colluvia, particularly on the eastern talus of the rift shoulder, that the deep, tectogenetic erosions are not capable of carrying away the material displaced by the population or the agricultural exploitation of the soil and by the accelerated slope erosion; this despite the high annual rainfall and substantial surface water runoff. The lower slopes are characterized by the accumulation of material in all particle sizes. Because of selective removal, finer soil textures remain on the upper slope areas [4].

Just as we can devise a regional classification for Rwanda's major geographic areas, we can also divide the country from a climatic perspective. Because it lies near the equator, Rwandan territory belongs to the inner or moist tropics. However, because of its altitude, the region of East Africa in effect must be differentiated between regional or local climates [5]. Following Köppen and Geiger [6], Rwanda is termed an Af climate, although during the dry winter season, an Aw climate could be attributed to it. Moreover, in consideration of the altitude and the average annual temperatures prevalent at the higher elevations, the more temperate $\mathrm{Cw}$ climate type would be appropriate for the conditions prevailing there. This transition from $\mathrm{Aw}$ to $\mathrm{Cw}$ occurs spatially approximately along the contours of the 1800 meter isohypse. At certain elevations in the Central Highlands and in the
Virunga volcano massif, frosty nights are not unusual. Mount Karisimbi possesses the only E climate. Thanks to the altitudes, Rwanda's temperatures diverge slightly from the daily temperature lows typical for the inner tropics. The mostly clear nights tend to produce strong cooling.

Windward and lee locations clearly influence the country's rainfall and how it is distributed. Along the windward side of the mountain ranges, it interacts with fertile, mineral-rich volcanic soils to produce highly favorable local conditions. The regions amount of rainfall varies between 1000 and $1500 \mathrm{~mm}$ [7]. Air masses arising from the seasonal shift of the intertropical convergence zone that are transported between the anticyclones of the northern and southern hemispheres shape Rwanda's climate. Two rainy seasons occur with a four-to-sixweek lag with respect to the sun's zenithal position. The first, so-called "big rain", usually starts in February and lasts into June. April is the month with the highest rainfall. It results from the converging northeasterly and southeasterly trade winds that blow during this time of year. Easterly winds carry moisture-laden air masses from the Indian Ocean to Central Africa. With the waning of the big rainy season in mid- to end-June, quite dependably time-wise comes the "great dry season" that settles in over much of the northern hemisphere from July to September influenced by the position of the tropical low pressure trough. When the intertropical convergence zone once again moves into Rwanda in November, it marks the peak of the "little rain". The little rainy season, too, is fed by moist air carried by the easterlies from the Indian Ocean. October and November probably qualify more or less as the rainiest months, a title that December might be thought to deserve, but by then rainfall is already sparse. This signals the transition to the "little dry season", characterized especially in January by the dry northeast trade winds under whose influence Rwanda falls this time of year.

The interplay of relief, altitude, exposure of the mountain ranges to the prevailing, rain-bearing easterly winds, but also the situation in basins and valleys reveal some clear regional, mesoscale climate divergences from the super ordinate global macroclimate (Figure 1).

\section{GOALS AND METHODOLOGY OF THE RECCIR PROJECT}

Analyses of climate measurement series from Rwandan weather stations revealed that the division into four Rwandan climate zones is not correct any more. This could be shown in a more detailed analysis based on currently available data. In the course of discussions held with the Service Meteo Rwanda, a department under the Ministère de L'Infrastructure, it emerged that the climate charts used in Rwandan atlases and school books are 
based on data covering the period from 1931 to 1960. Fortunately, since then a mass of new data have been collected, which, however, until now have only been evaluated in isolated instances for a specific local as needed. This led to the initiation of the ReCCiR project (Recent Climate Change in Rwanda) in 2009. The project's aim was to conduct a regional climatic analysis covering all of Rwanda and visualizing it on new maps.

For these purposes, we accessed the climate records from a total of 87 weather stations. As we began the project, this turned out to be an extremely large collection that seemed to augur well for making an easy task of evaluating Rwanda's climate situation based on local climates, not least in view of the fact that the weather stations (for the most part temperature and rainfall readings) were distributed throughout the country. In some cases, it was possible to rely on time series reaching back to 1927 . Up until the early 1990's, a majority of the recorded data based on the "Mannheim hours". That meant having to assume a certain degree of inaccuracy in the results when comparing manually derived data with continuous digitally recorded values. In order to be able to quantify this inaccuracy, we selected a location where we could record daily average temperature readings over a six months time horizon with representative data collection methods using both "Mannheim hours" as well as continuous readings. The choice fell on the save station, a monastic complex where local climate events have been tracked on the basis of "Mannheim hours" since the mid-1920's. This showed that the manual values differed from the digitally-logged ones by $3 \%$. This difference was then factored into subsequent analyses, well-knowing that it could not be considered as representative for all of Rwanda's weather stations, some of them were not equipped with the same measuring instruments as those used in designing the Save experiment. Nonetheless, this finding was regarded as a correction value.

The time-consuming manual transfer of data from the measurement books into a usable digital form accorded us the advantage of filtering out transcription errors or inconsistencies, such as the ones caused by faulty recording (such as $379.5^{\circ} \mathrm{C}$ instead of $37.95^{\circ} \mathrm{C}$ ). That meant eventually discarding $19 \%$ of the entire data collection. Another problem encountered in analyzing the results stemmed from the fact that some of the erstwhile 87 weather stations had changed their locations one or more times over the years. On-site visits determined if the new locations were comparable with the old ones. It turned out that for most stations this merely involved relocating them by a few meters, which was considered a non-relevant displacement since the substrate was the same. Whenever the two points turned out to be dissimilar, these stations were also eliminated from the data contingent. The same applied for stations that had been relocated several times but could no longer be tracked down. The only break in the measurement series was due to the genocide. Reliable values could only be recorded again from 1996 on. All in all, the number of usable weather stations now shrank to 51 . However, these were now available in digital form, and they still covered the country's entire territory.

In order to safeguard the statistical reproducibility of the climate measurement results, we first conducted a cluster analysis, which allowed separating the measurement station data into partial collectives or groups. The basis of the cluster analysis is a comparison of temporal patterns for the temperature curves. Group membership was assigned by Euclidean distance mapping. Data was compared using single-linkage cluster analysis. This involves comparing paired values and aggregating each most similar pair in a cluster (nearest neighbor technique; $[8,9])$. The first result to be drawn from this analysis was that the climate measurement series of the ultimately remaining stations fit very well into differentiated groups corresponding to relevant regional climate zones. This result was then subjected to hypothesis testing using a "student's" t-test. This answered the question of whether there were significant differences between the individual measurement stations or whether we were dealing with null hypotheses in the case of the calculated clusters, as if mapped in this form by simple chance [8,9]. It showed, that the weather stations, not being grouped in clusters of specific weather stations, with $\alpha<0.05(\mathrm{Si}=95 \%)$ also were not correlated, confirming the results of the cluster analysis.

Visualizing the area-wide development of the climatic changes, we resorted to a method of geostatistical interpolation. Specifically, we applied the kriging technique. Besides applying distance-based weights to neighboring points, it also weights them by the value of the neighboring point; i.e. a value that is to be interpolated is influenced more by points that lie closer to it than ones farther away. This prevents falsification through clustering as well as through the so-called "trained eye" effect. The kriging technique recommends itself as the optimal technique for geographical interpolation of diverse measurements. A sub-technique known as local ordinary kriging was used to present a picture of reality as accurate as possible. This results in not necessarily having to do trend elimination by means of a linear function, but by incorporating the twelve measurement points lying closest to the interpolation point in the calculation. The technique minimizes the likelihood of errors $[10,11]$.

\section{STATUS-QUO IN LITERATURE}

Basically, we can differentiate four regional Rwandan climate zones ranging from east to west, resulting in the following terrain as well as climatic picture: from the 
border with neighboring Tanzania in the east stretches the "East-Rwandan dry and hot lowland zone", a savanna climate which can be regarded as an extension of the Iwemberre steppe which lies to the east. Rising gradually from east to west, this zone tops out at elevations of about 1600 m.a.s.l. The annual average temperature reaches $21^{\circ} \mathrm{C}$ in this lowland zone while the mean annual rainfall reaches $899 \mathrm{~mm}$ (Figure 2). Due to the enormous extent of the East Rwandan lowlands, however, certain locales along the border with Tanzania diverge markedly from the annual averages. Drier expanses in the east exhibit localized rainfall amounts of $<800 \mathrm{~mm}$, in contrast to rainfall that can reach $>1000 \mathrm{~mm}$ in higher-situated areas of the lowland zones. Within the dry zone, southeast of Kigali, lies the "humidity island" of Kibungo. This area with rainfall that increases to just over 1000 $\mathrm{mm}$ contrasts with precipitation amounts in the $800 \mathrm{~mm}$ range. Where the annual rainfall is evenly distributed ranging between 900 and $1000 \mathrm{~mm}$, agriculture can be practiced. The adequate water supply and temperatures favor the cultivation of moisture-loving crops like cassava and sweet potatoes, even cotton in some places. Next comes the "Temperate zone of the central highlands (Figure 2), whose elevations increase from east to west, connecting to the "East-Rwandan dry and hot lowland zone", rainfall also increases markedly along with elevation with an annual temperatures average $19^{\circ} \mathrm{C}$, rainfall at $1200 \mathrm{~mm}$ is distinctly higher than in the eastern territories. The highlands remain free of frost up to 2500 m.a.s.l. Notably, the temperate zone's yearly temperature swings are less pronounced than those in the eastern lowlands. For that reason, the temperate highlands zone can be termed Rwanda's most extraordinarily fertile ag-

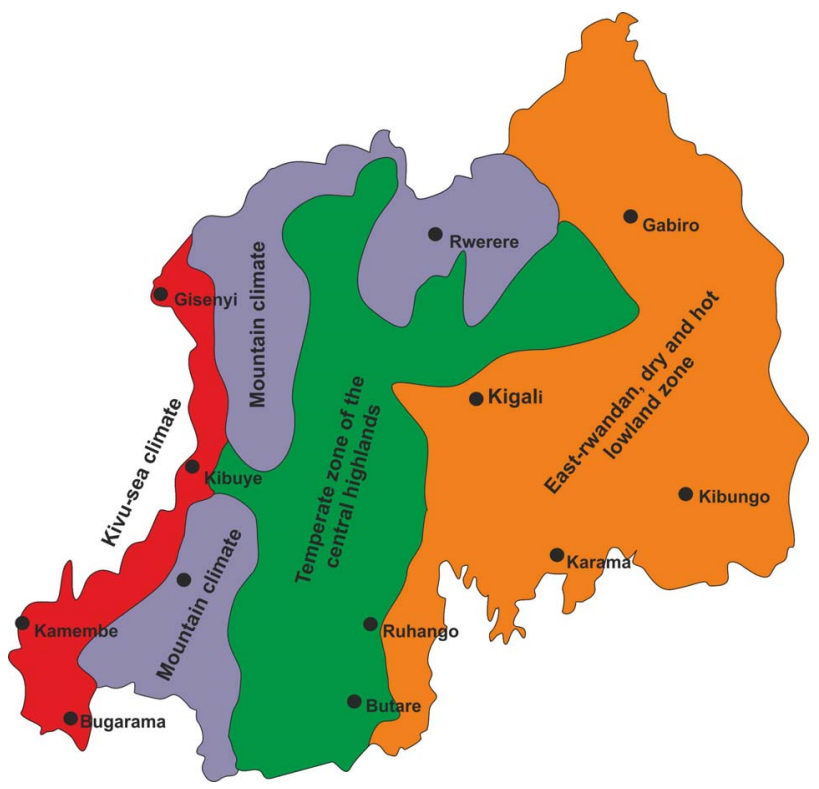

Figure 2. The climate zones of Rwanda, based on data from 1931-1960 (based on [13]). ricultural region. A consequence of the area's high food security is the enormous population pressure prevailing there. Although the population density in this region is not Rwanda's highest, it does exhibit consistently high numbers spread over the individual administrative units (e.g. Rutsiru and Rubavu, each with 500 - 1000 inh $\cdot \mathrm{km}^{-2}$ or Ruhango and Huye with $\left.500 \mathrm{inh} \cdot \mathrm{km}^{-2},[12]\right)$. The permanent crops in the Central Highlands are bananas and coffee. Cultivation is possible up to 2000 m.a.s.l. Based on location and altitude above sea level, a third localized climate zone can be distinguished from the rest of the country: In the south there is the mountain range of the Congo-Nile watershed ("Crête Congo-Nil"); the volcanic chain of the Virungas in the north (Figure 1). These areas can be described as Rwanda's "Mountain climate", with rainfall of $>1600 \mathrm{~mm}$ and temperatures that only reach $16^{\circ} \mathrm{C}$ (Figure 2). At about 2500 m.a.s.l. is Rwanda's cultivation limit. The Lake Kivu Rift Valley demarcates the fourth of Rwanda's local climate zones (Figure 2). The land-lake-wind circulation interacts with the high evaporation rates prevailing on Lake Kivu to create a distinct regional climate system. Due to the circulation, sufficient amounts of rain fall on the western slopes of the Congo-Nile watershed mountain range. This works to the local's climatic advantage, since it is actually in the lee of the Virunga volcano chain. Year-round temperatures that hover around $20^{\circ} \mathrm{C}$ endow the Lake Kivu region with a favorable climate. The Bugarama Rift Country abuts south of Lake Kivu. It is the southern part of the Rift Valley on Rwandan territory and here is also Rwanda's lowest point at 900 m.a.s.l. (Figure 1). With an average of $24^{\circ} \mathrm{C}$ and rainfall of about $1200 \mathrm{~mm}$, it is also the country's least favored region.

\section{RESULTS OF THE RECCIR-PROJECT}

Analyses of climate measurement series for the Rwandan weather stations began with evaluating the time series by decades, above all in order to understand the spatial changes in the regional and local climatic situation better. They showed some clear divergences from the picture drawn to date of climatic relationships in Rwanda, which still rest on a data base of normal climate period from 1931 to 1960 . The first minor local change within the respective climate regions already showed up in the comparison of values from 1931 to 1960 with the time series from 1960 to 1970 . But the changes in annual average temperatures and rainfall amount become even clearer when based on data between 1970 to 1990 , which also manifests itself eventually in the spatial distribution of the various climate regions.

An example of this development is depicted in Figure 3, using annual average temperatures for the time period 1971-2008. Even with the genocide-caused gaps in the measurement series, the trend is clearly one of tempera- 


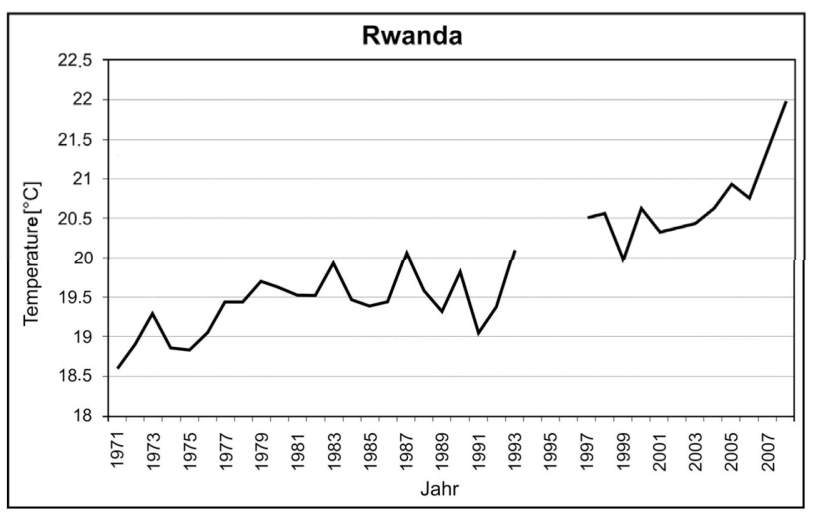

Figure 3. Annual average temperatures for the time period 1971-2008. The lack of data resulted by the Rwandan genocide.

ture rising.

The modification in rainfall totals during this measurement period is comparable, with a trend toward a decrease in the rainfall amount $(-240 \mathrm{~mm})$ evident. However, the rainfall distribution is subject to strong, regional variations.

Figure 4 plots a new, regional climatic division for the country based on 1996-2011 data. The manifest local climatic changes imply that Rwanda's old, four-part climate zone scheme no longer reflects the current situation. It is replaced by a new, six-part local or regional climatic breakdown.

As seen in Figure 4, the "East-Rwandan dry and hot lowland zone" spreads farther west. The 1000 meter isohyet, which can be regarded as the border to the "Central Highlands", has moved far beyond the metropolitan area of the capital city, Kigali. The rainfall total for Kigali now is just $900 \mathrm{~mm}$. In the entire climate zone, rainfall reaches maximum values of around $900 \mathrm{~mm}$ and the annual average temperature is $21^{\circ} \mathrm{C}$. Only the "humidity island" around Kibungo, due to the high evaporation rates over the adjoining water surfaces, exhibits rainfall $\geq 900$ $\mathrm{mm}$ (see Chapter 3). Because of the west-moving dryness, the climatic features of the "Temperate zone of the central highlands" are shifting east and to higher elevations. Comparable with the "East-Rwandan hot and dry lowland zone", rainfall is decreasing evidently in these areas as well $(-160 \mathrm{~mm})$, while on the other hand temperatures are increasing $(+1.2 \mathrm{~K})$. The most significant modification within the temperate climate zone can be observed in the high mountainous region around Rewere. Defined as "Mountain climate" under the old climate definition, in comparison with other Rwandan locations, this area registers the highest rainfall decline and a strong temperature increase that are anomalous for these altitudes. It is similar in the high mountain regions of the country's north and south (Figure 4). A markedly more temperate climate is evident on the Rift ridge and also on

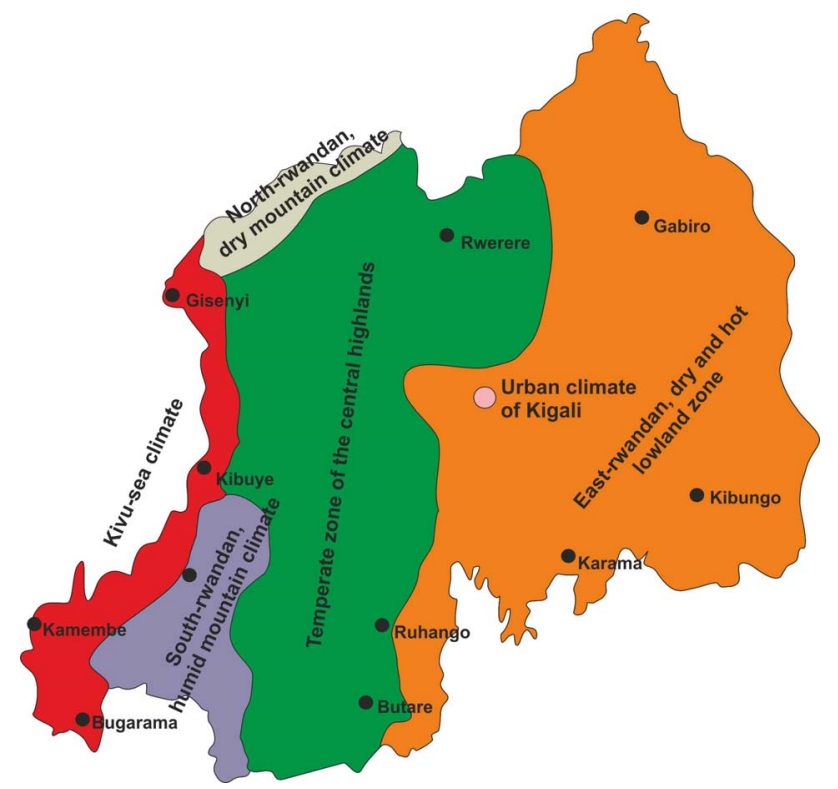

Figure 4. The new climatic classification of Rwanda, based on data from 1996-2011.

the Virunga volcano range.

Population pressures have been growing in recent years in these regions because of the changes in its climate. On top of the generally strong population growth rate, people are migrating from the eastern, drier parts of the country to the central highland in search of better farming conditions and food security. Due to the declining precipitation, cultivation of some agricultural products is no longer possible in parts of the "East-Rwandan hot and dry lowland zone" or only with great effort.

A physically nearly unchanged regional climate zone is the area along Lake Kivu. The already-mentioned local climate peculiarity arising from the prevailing land-lakewind circulation continues to cause climatic conditions that remain roughly the same, with slightly rising temperatures $(+0.5 \mathrm{~K})$ and a decrease in rainfall around 50 $\mathrm{mm}$ (Figure 4). Experiencing the most far-reaching climatic and physical changes is Rwanda's mountain climate, which used to be concentrated in the regions of the Virunga volcano chain in the north and the Nyungwe mountain rain forest in the south. This simple division can no longer be maintained regarding the current data. In fact, the local climates of the two regions must be demarcated from each other. While the area in southern Rwanda, especially around the Nyungwe rainforest, exhibits modest temperature changes $(+0.5 \mathrm{~K})$ and continues to register rainfall totals of $>1400 \mathrm{~mm}$, around the Virunga volcanos the temperatures range about $2 \mathrm{~K}$ higher while total rainfall has clearly dropped $(-250 \mathrm{~mm})$. This calls for a new division of the Rwandan mountain climate into a "South-Rwandan humid mountain climate" and a "North-Rwandan dry mountain climate" (Figure 4). 
The capital city, Kigali, occupies a special position. It has probably reached the mark of 1 million inhabitants ( $1000 \mathrm{inh} \cdot \mathrm{km}^{-2}$ [13]). For a long time, Kigali laid inside the $1000 \mathrm{~mm}$ isohyet in the transition zone between the temperate highland climate in the west and savanna climate in the east. In the present day, the city's entire catchment area must be assigned to the "East-Rwandan hot and dry lowland zone". Just the decline in rainfall totals by $110 \mathrm{~mm}$ reveals a shift of $1000 \mathrm{~mm}$ isohyet to the west. Moreover, an urban climate effect can be detected even for this rustic capital city that raises temperatures by an average $1.5 \mathrm{~K}$ above the surrounding countryside. Added to this is the highly polluted city air [14]. Consequently, Kigali was taken into the new classification as the sixth local climate zone (Figure 4).

\section{CONCLUDING REMARKS}

At present it is still difficult to account for the modifycations that climate change brings, particularly when trying to account for them on a regional or local scale. But by the results of the ReCCiR-Project it was possible to show that it is absolutely necessary to use long meteorological time series to have a conclusion about local climate modifications. Because, as it could be indicated for the Rwandan territory, temperature and precipitation modifications on a large scale could not be adequately reproduced by the global simulations used e.g. by the IPCC. So exemplarily, for years and years the mentioned part of sub-Saharan Africa, where also Rwanda is situated, the "Intergovernmental Panel on Climate Change" projects a significant increase of the amount of precipitation for this area. Though, the analysis of the ReCCiR-Project proves the opposite.

\section{REFERENCES}

[1] Battistini, R. and Sirven, P. (1981) Géomorphologie. Atlas du Rwanda, Planche IV.
[2] Petricec, V. (1981) Géologie. Atlas du Rwanda, Planche III.

[3] König, D. (1992) Erosionsschutz in agroforstsystemen. In: Mainzer Geographische Studien, Heft 37.

[4] Jätzold, R. (1981) Klimageographie-Ostafrika. In: Afrika-Kartenwerk, Beiheft 5, Gebrüder Bornträger, Stuttgart.

[5] Michael, T. (2008) Diercke weltatlas. Westermann Schroedel Diesterweg Schöningh Winklers GmbH, Braunschweig.

[6] Prioul, C. (1981) Précipitations. Atlas du Rwanda, Planche VI.

[7] Bamusananire, E., Byiringiro, J., Munkyakazi, A. and Ntagaramba, J. (2006) Macmillian Rwanda-Primary social studies. Macmillian Publishers, Oxford.

[8] Henninger, S. (2011) A mobile measuring methodology to determine near surface carbon dioxide within urban areas. In: Mazzeo, N., Ed., Air Quality-Models and Applications, InTech Press, Rijeka, 173-194. doi:10.5772/16549

[9] Schönwiese, C.D. (2006) Praktische statistik für meteorologen und geowissenschaftler. 4. Auflage, Gebrüder Bornträger, Berlin, Stuttgart.

[10] Stoyan, D. and Jansen, U. (1997) Umweltstatistik: Statistische verarbeitung und analyse von umweltdaten. Teubner Verlag, Leipzig.

[11] Siebertz, K., van Bebber, D. and Hochkirchen, T. (2010) Statistische versuchsplanung. Springer Verlag, Berlin, Heidelberg. doi:10.1007/978-3-642-05493-8

[12] Munyakazi, A. and Ntagaramba, J. (2006) Atlas du Rwanda. Macmillan Publishers, Oxford.

[13] Adimola, B., Gahima, C., Kivuva M. and Mmbando, J.S. (2006) Atlas for east Africa. Pearson Longman Press, Essex.

[14] Henninger, S. (2009) Urban climate and air pollution in Kigali, Rwanda. Proceedings of ICUC-07, Yokohama, 29 June-3 July 2009, 1038-1041. 